\title{
Parasitoids of the endangered leafcutter ant Atta robusta Borgmeier in urban and natural areas
}

\author{
Diego S. Gomes ${ }^{1}$, Luciana Elizalde² \& Jarbas M. Queiroz ${ }^{3,4}$
}

\footnotetext{
${ }^{1}$ Programa de Pós-Graduação em Biologia Animal, Instituto de Biologia, Universidade Federal Rural do Rio de Janeiro. 23890-000 Seropédica-RJ, Brazil.

${ }^{2}$ Laboratorio Ecotono, INIBIOMA, CONICET-UNCOMA, Pasaje Gutiérrez 1125, 8400, Bariloche, Argentina.

${ }^{3}$ Departamento de Ciências Ambientais, Instituto de Florestas, Universidade Federal Rural do Rio de Janeiro. 23890-000 Seropédica-RJ, Brazil.

${ }^{4}$ Corresponding author. jarquiz@gmail.com
}

\begin{abstract}
Parasitoids of the endangered leafcutter ant Atta robusta Borgmeier in urban and natural areas. Hosts of parasitoids in urban areas may suffer from a double threat of habitat destruction by urbanization and parasitism pressure. Moreover, the parasitoids themselves might be at risk if they are specialists. Here, we studied whether Atta robusta (Hymenoptera, Formicidae), which is on the red list of Brazilian threatened species, suffers from higher parasitism pressure in an urban area compared to a natural one. In addition, we determined whether their specialist parasitoids, Eibesfeldtphora breviloba and Myrmosicarius exrobusta (Diptera, Phoridae), are in risk and evaluated whether they are influenced by habitat structure, temperature, humidity, ant traffic, and time of the day. The study was carried out in an urban park and in a natural protected area in the city of Rio de Janeiro. In each site we chose an open area and a closed area (forest) and sampled nine nests in each area. We found that parasitism pressure was similar in urban and natural areas, with the same two parasitoid species present in both areas. The main difference was related to habitat structure, since M. exrobusta was mainly present in open areas while E. breviloba was almost exclusively found in closed areas. Myrmosicarius exrobusta was not present during the hottest midday times, and its abundance was negatively correlated to vapor pressure deficit. These results suggest that green areas can be an important component in efforts to conserve diversity in urban areas. However, the complexity of the habitats in those areas is a fundamental issue in designing urban parks.
\end{abstract}

KEYWORDS. Biodiversity; Insecta; leafcutters; Restinga; urban ecology.

Habitat destruction has been a major cause of current species extinctions. One type of habitat destruction is urbanization, although parks and green areas can maintain a high diversity of species, especially for those which are generalists (Samways 2005). Natural enemies, particularly parasitoids, are often quite affected by urbanization (Denys \& Schmidt 1998). Changes of parasitoid communities in urban areas are often associated with different environmental tolerances of species (Fenoglio et al. 2009). On the other hand, a high pressure of parasitism may be a threat to its host population (Lafferty \& Gerber 2002), especially if the host is already compromised by habitat destruction. Moreover, the host-parasite system may be at risk of coextinction if the host supports specialist parasites (Koh et al. 2004).

The leafcutter ant Atta robusta Borgmeier (Hymenoptera, Formicidae) is endemic to the restingas in the Brazilian states of Rio de Janeiro and Espírito Santo (Teixeira et al. 2004). The restingas are characterized by having sandy soils covered with herbaceous and shrub-arboreal vegetation located in coastal lowlands (Rocha et al. 2007). The degradation of the restinga resulting from anthropic pressures (Rocha et al. 2007) led A. robusta to be threatened with extinction (Machado et al. 2008). In fact, it was recently stated that the species was extinct in the city of Rio de Janeiro (Dattilo et al. 2012), but it is still possible to find A. robusta popula- tions in highly urbanized areas of this city (Brown et al. 2012). Its extinction may have important consequences for ecosystem functioning, because this species plays an important role as a seed disperser, helping the seeds of several species to germinate (Teixeira et al. 2008).

Flies of the family Phoridae are among the main natural enemies of leafcutter ants (Bragança 2011). The phorid flies that parasitize ants use the host's body to complete their life cycle, and their occurrence is restricted by certain conditions, such as habitat structure, temperature and relative humidity (Folgarait et al. 2007; Almeida et al. 2008; Elizalde \& Folgarait 2010). In addition, parasitoid abundance may depend on host foraging activity (Tonhasca Jr. 1996), and the form of attack or oviposition site (such as nest entrance holes or foraging trails) vary among phorid species (Erthal Jr. \& Tonhasca Jr. 2000; Bragança \& Medeiros 2006; Gazal et al. 2009; Elizalde \& Folgarait 2011, 2012). Recently, three species of phorid flies were described attacking workers of $A$. robusta, two of them were recorded only in Rio de Janeiro: Eibesfeldtphora breviloba Brown and Myrmosicarius exrobusta Brown (Brown et al. 2012). These phorid species are specialists on $A$. robusta (Brown et al. 2012).

In this study, we quantified the occurrence of E. breviloba and $M$. exrobusta in natural and urban environments of the city of Rio de Janeiro to evaluate whether parasitoid pres- 
sure differs in both environments. In addition, we analyzed the influence of habitat complexity structure (open vs. closed), to test whether a more complex and protected habitat supported more phorids. Then, we evaluated the effect of temperature, humidity, and ant traffic on the foraging activity of these phorid species. Lastly, we described some natural history aspects of these parasitoids, such as the site where parasitoids oviposit and phorid species co-occurrence in nests, because there is scarce information on phorids that attack $A$. robusta (Brown et al. 2012).

\section{MATERIAL AND METHODS}

Study areas. The study was carried out, between 2009 and 2010, in two sites: Parque Natural Municipal Marapendi (PNMM) and in Restinga da Marambaia (RM). These sites are $15 \mathrm{~km}$ apart, both located in the city of Rio de Janeiro. PNMM (231'4"S, $\left.43^{\circ} 26^{\prime} 54^{\prime \prime W}\right)$ has a total area of 195 ha and is located in a region of high population density, relatively isolated from other habitat fragments. RM $\left(23^{\circ} 2^{\prime} 47^{\prime \prime} \mathrm{S}\right.$, $\left.43^{\circ} 35^{\prime} 24^{\prime \prime} \mathrm{W}\right)$ is well preserved, has a total area of 5,000 ha, and is located in a region protected by a unit of the Brazilian Army. Hence, we will consider here PNMM an urban area and RM a natural habitat.

Experimental design and data collection. In each site we chose an open, less complex and less protected area (with predominance of grasses and few trees) and a closed area (forest) and sampled nine nests of $A$. robusta in each area, for a total of 36 nests in the two sites. Observation and data collection over each nest began at 9:00h, and ended after eight intervals of $45 \mathrm{~min}$. At each interval we collected all phorid flies attacking ants in nest entrance holes and trails, and labeled them accordingly. Although the sampling implied parasitoid removal, we found parasitoids at the beginning and at the end of sampling over nests. We later identified them under a binocular microscope. We also recorded temperature and air humidity using a wet and dry bulb hygrometer. We measured ant traffic by counting the number of ants passing a point of a foraging trail for 15 minutes.

Statistical analysis. To evaluate whether ant nests in urban areas suffered higher parasitism, we tested for an effect of urbanization on pooled phorid abundance, i.e. each nest represented a replicate, using Kruskal-Wallis ANOVA, because data were not normal. We also evaluated the effect of urbanization on the abundance of each phorid species with a Kruskal-Wallis ANOVA. Then, we tested for the effect of habitat structure, i.e. open or closed, on overall phorid abundance over nests, and for each parasitoid species using Kruskal-Wallis ANOVAs.

To determine if foraging phorid flies of each species were influenced by the effect of environmental variables (temperature and relative humidity), traffic of worker ants, or showed a daily pattern of activity, we used logistic mixed models (Zuur et al. 2009). Because of our sampling design, we used nest identity as a random variable (to consider the repeated measurements over time on each nest) nested within each habitat (because nests in each area are closer to each other). We first evaluated with GAMM (generalized additive mixed models) whether the relationships with the variables were non-linear. Otherwise we used GLMM (generalized linear mixed models). We used the presence of phorids, applying logistic models, instead of abundance because most of the 45 minute periods had only 1 phorid (see Results). Interactions between variables were not significant.

We tested for an effect of these environmental variables on the abundance of parasitoids. Due to the low abundance of phorids in each sampling period (see Results), we added phorid abundance by phorid species for each sampling time for all nests sampled. We averaged temperature, humidity and traffic for all ant nests in each period. However, because average temperature and average humidity were highly correlated $(\mathrm{r}=-0.98, \mathrm{df}=6, \mathrm{P}<0.001)$, and to reduce the number of variables in a model with only 8 points, we obtained average vapor pressure deficit, a variable that combines information from temperature and humidity, and is an important ecological variable (Anderson 1936). We evaluated the relationship between the abundance of each phorid species and these variables using multiple linear regressions. By averaging the values between different nests, the effect of repeated sampling on each nest is reduced, as well as the wide variability in the independent variables.

We examined where parasitoid species attacked their host in different microsites, i.e. nest entrances or foraging trails by comparing their abundance with chi-squared tests. We used $\mathrm{R}$ environment to perform statistical analyses ( $\mathrm{R}$ development Core Team 2009), with "mgcv" package for the logistic additive mixed models (Wood 2012) and "lme4" package to run the logistic linear mixed models (Bates et al. 2012).

\section{RESULTS}

Phorid parasitism pressure, measured by parasitoid abundance, was the same for nests of Atta robusta in the urban or natural area (Kruskal-Wallis $\chi_{1}^{2}=0.045, \mathrm{P}=0.83, \mathrm{~N}=36$ ), and most nests located in natural or urban habitat were attacked by parasitoids ( 89 and $83 \%$, respectively). Each of the two parasitoid species collected attacking this ant, Myrmosicarius exrobusta and Eibesfeldtphora breviloba, also did not show different abundance in natural or urban nests (Kruskal-Wallis $\chi_{1}{ }_{1}=1.22, \mathrm{P}=0.27, \mathrm{~N}=36$; Kruskal-Wallis $\chi_{1}^{2}=0.90, \mathrm{P}=0.34, \mathrm{~N}=36$; respectively). Phorid abundance was higher in nests located in closed areas (Fig. 1; Kruskal-Wallis $\chi_{1}^{2}=7.62, \mathrm{P}=0.006, \mathrm{~N}=36$ ), due to the higher overall abundance of E. breviloba in closed areas (Fig. 1; Kruskal-Wallis $\chi_{1}^{2}=22.75, \mathrm{P}<0001, \mathrm{~N}=36$ ), while $M$. exrobusta showed higher abundance on nests located in open areas (Fig. 1; Kruskal-Wallis $\chi_{1}^{2}=12.07, \mathrm{P}<0.001, \mathrm{~N}=36$ ). In fact, only $4 \%$ of $E$. breviloba attacked ants in open habitats, and $15 \%$ of $M$. exrobusta attacked ants in the closed habitat. In addition, some nests located in the open habitat did not have any phorid attack (28\%), while all nests in the closed habitat had parasitoids. 


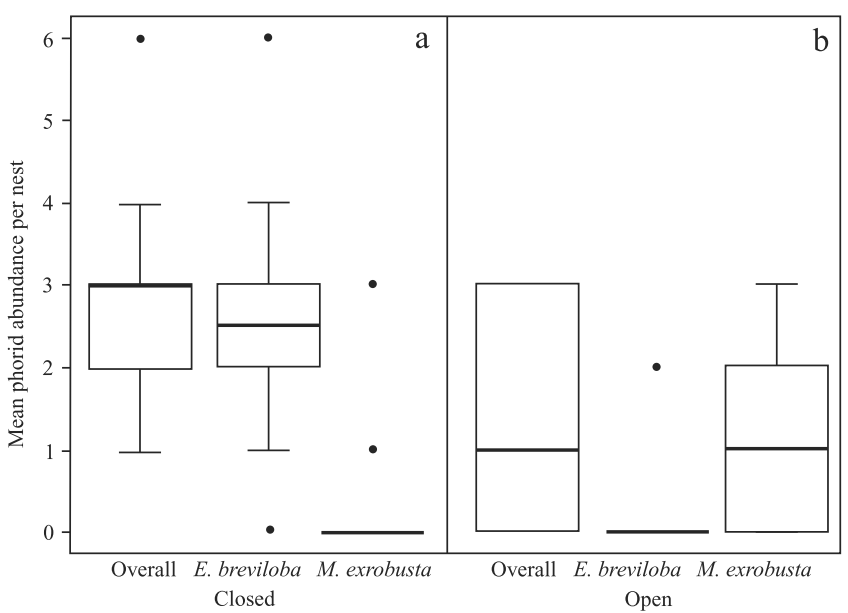

Fig. 1. Overall phorid abundance per nest and abundance by species attacking workers of Atta robusta in closed or open habitat in the city of Rio de Janeiro.

Nests of Atta robusta located in closed habitats were exposed to higher relative humidity than in open habitats (Kruskal-Wallis $\chi_{1}^{2}=57.83, \mathrm{P}<0.001, \mathrm{~N}=144,67.5$ vs. $59.0 \%$, median for closed vs. open habitats) but similar average temperature (Kruskal-Wallis $\chi_{1}^{2}=2.26, \mathrm{P}=0.13, \mathrm{~N}=$ 144,28 vs. $27^{\circ} \mathrm{C}$, median for closed vs. open habitats). However, variation in daily temperature was stronger in open habitats (Fig. 2a), and relative humidity varied similarly in both habitats along sampling times (Fig. 2b).

Because of the low occurrence or complete absence of $M$. exrobusta and E. breviloba in closed and open habitats respectively, phorid presence was modeled with the dataset from the habitat were each species was frequently found. Thus, the presence of $M$. exrobusta in open habitats had a curvilinear relationship with the sampling time (Time: $\mathrm{F}=$ 6.47 , degrees of freedom $=1.89, \mathrm{P}=0.003$ ), with the lowest probability of presence during midday (Fig. 3), the other variables being not significant. None of the variables measured were important in explaining the presence of $E$. breviloba in closed habitats ( $\mathrm{P}>0.30$ for all variables). No interactions were recorded between variables (all $\mathrm{P}>0.1$ ). In both models, almost no random variation was due to habitat, and variation among nests was very low (logistic additive mixed model for the presence of Myrmosicarius exrobusta: variance of random effects: Nest $=0.0002$, Habitat $=0$, AIC $=741.2, \mathrm{~N}=140$; logistic linear model for the presence of Eibesfeldtphora breviloba: variance of random effects: Nest $=0.00$, Habitat $=0.00, \mathrm{AIC}=172.1, \mathrm{~N}=144)$.

The abundance of $M$. exrobusta in open habitats showed a negative relationship with vapor pressure deficit (partial multiple linear regression coefficient $=-20.26, \mathrm{P}=0.04$, model $\left.\mathrm{R}^{2}=0.71\right)$, but no relationship was found with ant traffic $(\mathrm{P}=0.27)$. The abundance of E. breviloba in closed habitats did not show any relationship with these variables.

No differences were found for oviposition sites, i.e. trails or nest holes, for either species (M. exrobusta: $\chi_{1}^{2}=0.92 ; \mathrm{P}$ $>0.05 ;$ E. breviloba: $\left.\chi^{2}{ }_{1}=0.87 ; \mathrm{P}>0.05\right)$. The presence of
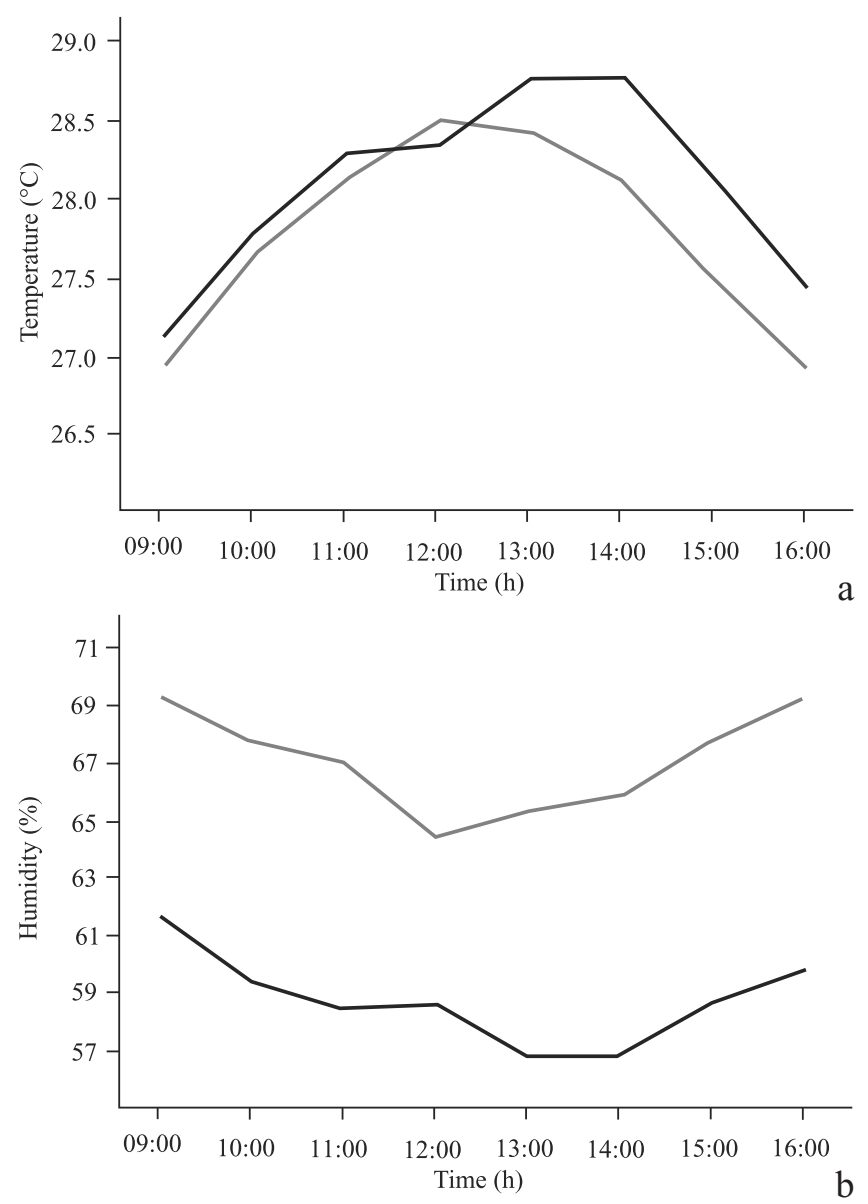

Fig. 2. Average temperature (a) and relative humidity (b) across time, for closed (grey line) and open (black line) habitats.

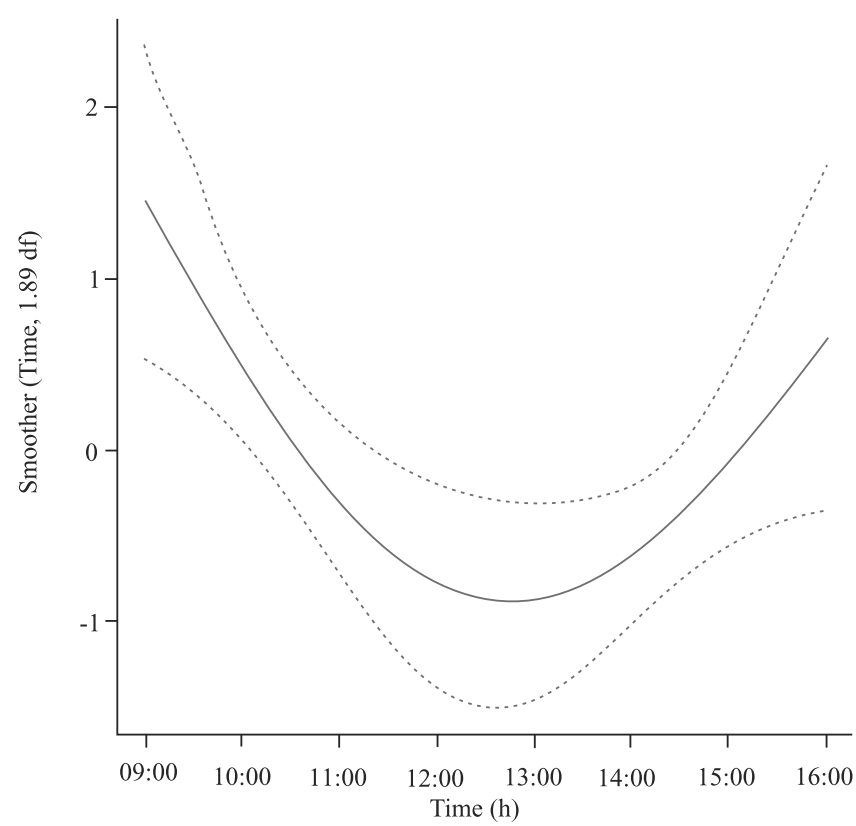

Fig. 3. Estimated smoothing curve for the effect of time of collection on the probability of presence of Myrmosicarius exrobusta. The y-axis shows the contribution of the time smoother to the fitted values (solid line; dotted lines are $95 \%$ confidence bands). 
phorid flies near the nest holes often led A. robusta workers to abandon the plant fragment they were carrying and return quickly into the nest. In addition, we observed that some $M$. exrobusta flies started chasing ants on the trail but only attacked them near the nest hole.

\section{DISCUSSION}

In this study we found that parasitism pressure on Atta robusta did not differ between a natural area and an urban park. In fact, the two parasitoid species were found attacking their host both in natural and urban areas. This suggests, as other recent studies showed (see Samways (2005) for a review), that both green areas and parks can be important in conserving diversity in urban areas. However, our results show that it is important to consider the complexity of the habitat, because E. breviloba attacked ants almost exclusively in closed habitats while $M$. exrobusta was found attacking its host in open habitats.

Habitat structure seems to be an important factor for the understanding of the spatial distribution of ant parasitoids (Folgarait et al. 2007; Elizalde \& Folgarait 2010; but see Reese \& Philpott 2012). For example, phorid fly species that attack Solenopsis invicta in agroecosystems are associated with annual open crops or closed perennial crops (Almeida \& Queiroz 2009). Habitat structure affects microclimatic conditions and resource availability for the species, which may result in differences in parasitism rates by both dipteran and hymenopteran parasitoids (De La Mora \& Philpott 2010; Vasquez-Ordonez et al. 2012; Pardee \& Philpott 2011). Although the association of E. breviloba with closed areas and of $M$. exrobusta with open areas is probably related to environmental conditions, we did not find a relationship between phorid presence and either temperature or humidity. Only in relation to the abundance of $M$. exrobusta there was a negative relationship with vapor pressure deficit. Because this species is smaller than E. breviloba (Brown et al. 2012) and is associated with open areas, it is more exposed to extreme climatic conditions, which limited its foraging opportunities during the hottest times of the day. However, E. breviloba may attack $A$. robusta at any time of the day (the time variable was not significant in the models), possibly because the forest protects the individuals of this species against adverse conditions.

However, we could not exclude habitat segregation mediated by competition between these phorid species as a mechanism to explain the higher abundance of each species in different habitats. The two species were collected attacking $A$. robusta at the same time in only one nest, suggesting that competitive exclusion could be accounting for the pattern found here. The open habitat seems to be a harsher habitat than the closed one, due to the higher temperature and low relative humidity, and because all nests without parasitoids were located in this habitat. Thus, it might be possible that $E$. breviloba excludes $M$. exrobusta from closed forest sites, forcing it to attack in harsher conditions. Two studies demonstrate that the parasitoid Pseudacteon curvatus, attacking invasive Solenopsis ants, behaviorally displaces $P$. tricuspis from the sites were it prefers to oviposit (LeBrun et al. 2009; Porter \& Calcaterra 2013). To determine conclusively which mechanism is involved, experimental assays are necessary in this system.

Although some studies evidenced the preference of phorid flies for specific attack sites (Tonhasca Jr. et al. 2001; Bragança et al. 2003; Elizalde \& Folgarait 2012), in the present study there was no significant difference in the number of parasitoids captured between trails and nest holes. Different oviposition sites could be important in segregating host resource by parasitoids. However, because the same ant forager goes through the same entrance hole and foraging trail (Elizalde \& Farji-Brener 2012), this might not be a form of host segregation, as are other microsites such as external refuse piles or cutting sites (Elizalde \& Foglarait 2012).

The threats to the few remaining forests in the area of occurrence of $A$. robusta, i.e. the coast from Rio de Janeiro to Espírito Santo, in Brazil, may endanger the survival of $E$. breviloba. The urban parks are an important component for biodiversity conservation of the remaining restingas in the highly urbanized areas in the city of Rio de Janeiro. However, special emphasis should be placed on the design of those urban green areas, in order to include an array of habitats, for example, that both open and closed areas are available for species with different requirements.

\section{ACKNOWLEDGMENTS}

We thank Fundação Parques \& Jardins, from Rio de Janeiro City Hall, and CAEx-Marambaia, from Brazilian army for the permissions to work in the areas. CAPES granted DSG a scholarship and FAPERJ granted JMQ a scholarship (Proc.101.472/2010). LE thanks Fundación Bunge y Born (Argentina). We also thank Stacy Philpott and two anonymous referees for their critical reading and suggestions on a previous version of the manuscript.

\section{REFERENCES}

Almeida, F.S., Queiroz, J.M. 2009. Efeito da estrutura de habitat sobre a abundância de parasitóides Pseudacteon Coquillett (Diptera, Phoridae) em ninhos de Solenopsis invicta Buren (Hymenoptera, Formicidae). Revista Brasileira de Entomologia 53: 461-465.

Almeida, W.R., Wirth, R., Leal, I.R. 2008. Edge-mediated reduction of phorid parasitism on leaf-cutting ants in a Brazilian Atlantic forest. Entomologia Experimentalis et Applicata 129: 251-257.

Anderson, D.B. 1936. Relative humidity or vapor pressure deficit. Ecology 17: 277-282.

Bates, D., Maechler, M. \& Bolker, B. 2012. Ime4: Linear mixed-effects models using S4 classes. R package version 0.999999-0.

Bragança, M.A.L. 2011. Parasitóides de formigas cortadeiras, p. 321343. In: Della-Lucia, T.M.C. (ed.) Formigas Cortadeiras: da bioecologia ao manejo. Viçosa, Editora da UFV, $421 \mathrm{p}$.

Bragança, M.A.L., Della-Lucia, T.M.C. \& Tonhasca Jr, A. 2003. First record of phorid parasitoids (Diptera: Phoridae) of the leaf-cutting ant Atta bisphaerica Forel (Hymenoptera: Formicidae). Neotropical Entomology 32: 169-171. 
Bragança, M.A.L. \& Medeiros, Z.C.S. 2006. Ocorrência e características biológicas de forídeos parasitóides (Diptera: Phoridae) da saúva Atta laevigata (Smith) (Hymenoptera: Formicidae) em Porto Nacional, TO. Neotropical Entomology 35: 408-411.

Brown, B.V., Bragança, M.A.L., Gomes, D.S., Queiroz, J.M. \& Teixeira M.C. 2012. Parasitoid phorid flies (Diptera: Phoridae) from the threatened leafcutter ant Atta robusta Borgmeier (Hymenoptera: Formicidae). Zootaxa 3385: 33-38.

Dáttilo, W., Falcão, J.C.F. \& Teixeira, M.C. 2012. Predictive model of distribution of Atta robusta Borgmeier 1939 (Hymenoptera: Formicidae): subsidies for conservation of a Brazilian leaf-cutting ant endangered species. Studies on Neotropical Fauna and Environment 48: 193-201.

De La Mora, A. \& Philpott, S.M. 2010. Wood-nesting ants and their parasites in forests and coffee agroecosystems. Environmental Entomology 39: 1473-1481.

Denys, C. \& Schmidt, H. 1998. Insect communities on experimental mugwort (Artemisia vulgaris L.) plots along an urban gradient. Oecologia 113: 269-277.

Elizalde, L. \& Folgarait, P.J. 2010. Host diversity and environmental variables as determinants of the species richness of the parasitoids of leaf-cutting ants. Journal of Biogeography 37: 2305-2316.

Elizalde, L. \& Folgarait, P.J. 2011. Biological attributes of Argentinian phorid parasitoids (Insecta: Diptera: Phoridae) of leaf-cutting ants, Acromyrmex and Atta. Journal of Natural History 45: 2701-2723.

Elizalde, L. \& Farji-Brener, A. 2012. To be or not to be faithful: flexible fidelity to foraging trails in the leaf-cutting ant Acromyrmex lobicornis. Ecological Entomology 37: 370-376

Elizalde, L. \& Folgarait, P.J. 2012. Behavioral strategies of phorid parasitoids and responses of their hosts, the leaf-cutting ants. Journal of Insect Science 12: 1-26.

Erthal Junior, M. \& Tonhasca-Junior, A. 2000. Biology and oviposition behavior of the phorid Apocephalus attophilus and the response of its host, the leaf-cutting ant Atta laevigata. Entomologia Experimentalis et Applicata 95: 71-75.

Fenoglio, M.S, Salvo, A. \& Estallo, E.L. 2009. Effects of urbanisation on the parasitoid community of a leafminer. Acta Oecologica 35: 318-326.

Folgarait, P.J., Patrock, R.J.W. \& Gilbert, L.E. 2007. Associations of fire ant phorids and microhabitats. Environmental Entomology 36: 731-742.

Gazal, V., Bailez, O. \& Viana-Bailez, A.M. 2009. Mechanism of host recognition in Neodohrniphora elongata (Brown) (Diptera: Phoridae). Animal Behavior 78: 1177-1182.

Koh, L.P., Dunn, R.R., Sodhi, N.S., Colwell, R.K., Proctor, H.C. \& Smith, V.S. 2004. Species coextinctions and the biodiversity crisis. Science 305: $1632-1634$

Lafferty, K.D. \& Gerber, L.R. 2002. Good medicine for conservation biology: the intersection of epidemiology and conservation theory. Conservation Biology 16: 593-604.
LeBrun, E.G., Plowes, R.M. \& Gilbert, L.E. 2009. Indirect competition facilitates widespread displacement of one naturalized parasitoid of imported fire ants by another. Ecology 90: 1184-1194

Machado, A.B.M., Drummond, G.M. \& Paglia, A.P. 2008. Livro VermeIho da Fauna Brasileira Ameaçada de Extinção, vol. 1. 1st. ed. Brasilia, Ministério do Meio Ambiente, 1420 p.

Pardee, G.L. \& Philpott, S.M. 2011. Cascading indirect effects in a coffee agroecosystem: effects of parasitic phorid flies on ants and the coffee berry borer in a high-shade and low-shade habitat. Environmental Entomology 40: 581-588.

Porter, S.D. \& Calcaterra, L.A. 2013. Dispersal and competitive impacts of a third fire ant decapitating fly (Pseudacteon obtusus) established in north central Florida. Biological Control 64: 66-74.

R Development Core Team. 2009. R: A Language and Environment for Statistical Computing. R Foundation for Statistical Computing, Viena, Austria.

Reese, K.M. \& Philpott, S.M. 2012. Environmental and habitat drivers of relative abundance for a suite of Azteca-attacking Pseudacteon phorid flies. Environmental Entomology 41: 1107-1114

Rocha, C.F.D., Bergallo, H.G., Van Sluys, M., Alves, M.A.S. \& Jamel, C. E. 2007. The remnants of restinga habitats in the Brazilian Atlantic Forest of Rio de Janeiro state, Brazil: habitat loss and risk of disappearance. Brazilian Journal of Biology 67: 263-273.

Samways, M.J. 2005. Insect Diversity Conservation. New York, Cambridge University Press, 342 p.

Teixeira, M.C., Santos, I.A. \& Schoereder, J.H. 2008. Atta robusta: endemismo, extinção ou ausência de estudos? p. 359-367. In: Vilela, E.F., Santos, I.A., Schoereder, J.H., Serrão, J.E., Campos, L.A.O. \& Lino-Neto, J. Insetos Sociais: da biologia à aplicação Viçosa, Editora da UFV, 442 p.

Teixeira, M.C., Schoereder, J.H. \& Louzada, J.N.C. 2004. Occurrence of Atta robusta Borgmeier (Hymenoptera: Formicidae) in the north of Espírito Santo State, Brazil. Neotropical Entomology 33: 265-266.

Tonhasca Jr, A. 1996. Interactions between a parasitic fly, Neodohrniphora declinata (Diptera: Phoridae), and its host, the leaf-cutting ant Atta sexdens rubropilosa. Ecotropica 2: 157-164.

Tonhasca Jr, A., Bragança, M.A.L. \& Erthal Jr, M. 2001. Parasitism and biology of Myrmosicarius grandicornis (Diptera, Phoridae) in relationship to its host, the leaf-cutting ant Atta sexdens (Hymenoptera, Formicidae). Insectes Sociaux 48: 154-158.

Vásquez-Ordóñez, A.A., Armbrecht, I. \& Pérez-Lachaud, G. 2012. Effect of habitat type on parasitism of Ectatomma ruidum by eucharitid wasps. Psyche 2012: 1-7.

Wood, S. 2012. Mixed GAM Computation Vehicle with GCV/AIC/REML smoothness estimation. Version 1.7-22.

Zuur, A.F., Ieno, E.N., Walker, N.J. \& Saveliev, A.A., Smith, G.M. 2009. Mixed Effects Models and Extensions in Ecology with R. New York, Springer, $574 \mathrm{p}$ 